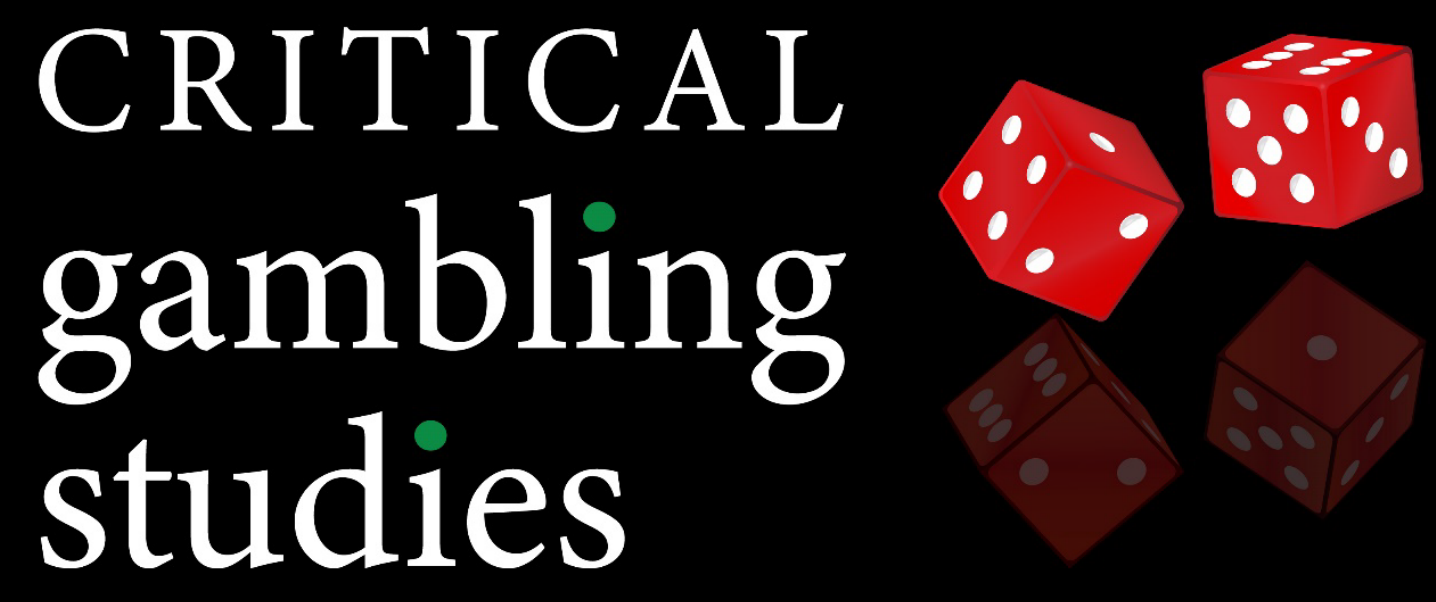

ISSN: 2563-190X. Available Open Access at https://criticalgamblingstudies.com

\title{
Evolving Understandings of Bingo in Four Decades of Literature: From Eyes Down to New Vistas
}

Kathleen Maltzahn, John Cox, Sarah MacLean, Mary Whiteside, Helen Lee

APA Citation: Maltzahn, K., Cox, J., MacLean, S., Whiteside, M., \& Lee, H. (2022). Evolving Understandings of Bingo in Four Decades of Literature: From Eyes Down to New Vistas.

Critical Gambling Studies, 3(1), 110-120. https://doi.org/10.29173/cgs89

Article History:

Received 2020-12-21

Accepted 2021-05-27

Published 2022-03-07 


\title{
Evolving Understandings of Bingo in Four Decades of Literature: From Eyes Down to New Vistas
}

\author{
Kathleen Maltzahn ${ }^{\mathrm{a}}{ }^{1}, \mathrm{~J} \mathrm{~h} n \mathrm{Cox}{ }^{\mathrm{a}}$, Sarah MacLean ${ }^{\mathrm{a}}$, Mary Whiteside ${ }^{\mathrm{a}}$, Helen Lee ${ }^{\mathrm{a}}$ \\ ${ }^{\text {a }}$ La Trobe University
}

\begin{abstract}
Bingo is a distinct, enduring but understudied form of gambling. It provides comfort and pleasure to many of its players while also causing harm to some. While traditionally seen as low harm, it is being reshaped by technological and regulatory change. Despite this, there is no recent overview of the literature on bingo. In response, this narrative review explores the development of literature on bingo since the 1980s, first providing a chronological overview of writing on bingo and then a brief account of major themes in the literature. The literature reviewed was primarily identified through searches of academic databases using search terms such as betting, bingo, electronic and gambling. We find that bingo research makes a number of important contributions: it allows better understanding of groups of overlooked gamblers, corrects biases in gambling literature against bingo as a site of study, highlights the importance of social and structural factors in understanding gambling and employs methodological approaches that are congruent with the people and practices being studied. Additionally, it provides new perspectives on gambling in terms of skill, affect, harm and control and offers a distinct viewpoint to analyse gambling and other phenomena.
\end{abstract}

Keywords: Bingo, gambling, harm, regulation, narrative review

Article History: Received December 21, 2020; Accepted May 27, 2021; Published March 7, 2022

Available Open Access from https://doi.org/10.29173/cgs89

\section{Introduction}

Bingo is an anomalous and often denigrated form of gambling (Downs, 2009; O'Brien Cousins \& Witcher, 2004), played by a minority of gamblers who are disproportionately women, older, working class and Indigenous (Moubarac et al., 2010). As such, it provides a counterpoint to more widespread forms of gambling and researchers have argued that bingo's failure to sit neatly within conventional scholarly categorisations of and theories about gambling forces us to re-examine dominant explanations of gambling (Bedford, 2019). However, there is no recent comprehensive overview of bingo literature or what contribution a better understanding of bingo can make to different academic fields, from gambling studies to political economy. The aim of this review, therefore, is to provide an overview of and critically analyse key literature on bingo, with a view to identifying major topics, themes and developments over time. Our study starts by tracing writing on bingo from the 1980s to the present, then briefly explores some key themes in the literature, including skill, affect, harm ${ }^{2}$ and control. Our conclusion examines the explanatory potential of using bingo as a lens to look at a wide range of issues, and how insights from the study of bingo can contribute to scholarship in gambling and beyond.

\section{Method}

This is a narrative review (Bryman, 2016) that identifies key English-language literature related to bingo. Narrative reviews are useful when providing a broad overview of an area, particularly of studies with varied methodologies and theoretical approaches where assessment of statistical evidence is not central. They are particularly suitable for use in studies examining the history of an area of research or theories (Green, Johnson, \& Adams, 2006; Siddaway, Wood, \& Hedges, 2019). Material was first identified through library searches conducted using electronic databases including Cinahl, Informit, Proquest and Psyclnfo. Search terms included betting, bingo, electronic, gambling, gaming and wagering and covered literature

\footnotetext{
${ }^{1}$ Corresponding author. Email: k.maltzahn@latrobe.edu.au

${ }^{2}$ In describing aspects of harm caused by gambling, we prefer the term gambling harm; where this does not adequately convey authors' meanings, we use their terminology.
} 
published after 2000. An initial search was conducted in May 2018 and was then updated in October 2019 and December 2020. Identified material was later supplemented in two ways: first by searches for grey literature conducted via Google Scholar and Duck Duck Go and material from the researchers' libraries and then by systematically searching the references lists of articles, including going back to the 1980s to include 11 earlier works. Literature that made a significant contribution to understanding bingo was included, even where bingo was not the sole or primary focus of the study. A total of 72 references, including grey literature, were read and to aid analysis, a database of evidence was developed: we categorised texts in an Excel spreadsheet according to a range of criteria and topics developed through discussion among authors. This analysis assisted identification of patterns, themes and disjunctures in the literature.

Much of the literature was exploratory, particularly early works. Not surprisingly, as is typical of gambling research, a portion of the research came from gambling studies and psychology and included prevalence surveys. However, unlike mainstream gambling research, the literature has a distinct ethnographic and sociological character, often centering the voices and experiences of bingo players. It draws on diverse disciplines and methodologies, from socio-legal approaches and discourse analysis to anthropology, leisure studies and history.

\section{Evolution of Bingo Research}

Our broad chronological overview of the literature describes the evolution of bingo literature over four decades, starting from the 1980s. We canvas key writers and themes and describe continuities and disjunctures in the literature over time.

\section{Eyes Down in the 1980s - Starting to Study Bingo}

While forms of bingo have been played for hundreds of years (Downs, 2007; Moubarac et al., 2010), it is only since the early 1980s that bingo has received serious scholarly attention. That attention began in the United Kingdom with a seminal study by leisure researchers Rachel Dixey and Margaret Talbot, who chose bingo as "the only activity which working class women do, outside the home, in any great numbers" (1982, p. 11). Dixey and Talbot (1982) placed bingo within a centuries-old practice of gambling, including by UK women, linking bingo back to "tumbule" in seventeenth century Italy, lotto in 1880s Britain and housey-housey and tombola in the army and navy. ${ }^{3}$ They described the way bingo was shaped by social changes, such as the commercialisation of entertainment, and legal changes, such as new gambling regulations, the latter theme a notable presence in subsequent UK bingo research (Downs, 2010; Bedford, 2016). Importantly, again setting the tone for subsequent bingo research, they looked outside the bingo hall to examine bingo in the context of women's leisure, social and economic roles and relations.

Dixey and Talbot learned that bingo was popular, widely played and overwhelmingly a women's game, in large part because it overcame hurdles to women's leisure by being local, predictable and safe. It was affordable, a key point when even women doing paid work were unlikely to control household cash. Counterintuitively, as a game of chance, rather than skill, it was a source of control: players did not have to feel under pressure to play well as winning was out of their hands. This was not to say that players did not care about winning, which was a thrill, money to take home and often a more realistic way to accrue a lump sum than saving. Significantly, despite these reasons, Dixey and Talbot argued that bingo was one choice among limited choices for working class women who lacked the leisure options of men and middle-class women. These findings would be reiterated consistently in later bingo research.

Dixey and Talbot's study exemplified in three ways some distinctive features of later bingo research. First, while other gambling literature often comes out of psychology, frequently focusing on the individual pathology of gamblers (Fiske, 2015), writing on bingo is decidedly more likely to be sociological or ethnographic (examples include O'Brien Cousins \& Witcher, 2004; Maclure et al., 2006; Dudar, 2009; Alexeyeff, 2011; Fiske, 2015) and to explore the way individuals and communities negotiate structural constraints (Alexeyeff, 2011; Bedford, 2018; Maltzahn et al., 2019; Cox et al., 2021). Second, it takes the players it studies seriously, often explicitly defending them against gendered, classed, aged and racialised biases that dismiss them as stupid, vulnerable or dull (O'Brien Cousins, 2004; Downs, 2009, 2011; Fiske, 2015; Bedford, 2019). It does this in part by making visible the social construction of bingo players. This allows fresh ways of understanding gambling and gamblers, particularly as experienced by women, working class, older and Indigenous people. Finally, bingo research is often expansive, examining bingo as a form, a setting and a practice of gambling, as well as a viewpoint to understand anything from women's leisure, to class, public space, and neoliberalism (Alexeyeff, 2011; Fiske, 2015; Bedford, 2019).

In a parallel approach to Dixey and Talbot at a similar time, in the United States, Kim King (1985) was studying bingo parlours. She brought a sociological sensibility to the analysis of gambling data, arguing that psychological studies of gambling had pathologised gamblers. Seeing gamblers as abnormal, she contended, failed to adequately account for the millions of "normal" people who regularly gambled. Equally, she noted that sociological attempts to correct this were weakened by lumping different gambling forms

\footnotetext{
${ }^{3}$ No period given.
} 
together. To address this, King studied bingo, lottery and an illegal form of lottery called numbers, finding that different groups of players had different subjective experiences of and within different types of gambling: for example, people had different motivations for lotteries than numbers, and men played bingo for different reasons from women. She contended that the structures of games and, more broadly, the social structures that shape players' lives, were more significant in helping understand players' motivations than classifications of skill or chance. Further, King (1990) argued that players managed the perception that bingo was morally ambiguous by emphasising its charitable nature, and minimised ideas that bingo might require skill as a way of downplaying the possibility that they were gambling out of self-interest. Consequently, she suggested ignoring categories of skill versus chance and instead examining "elements such as rules, degree of contact with workers, legitimacy of the game [and] how the players define the game..." (King, 1985, p. 247). King (1990) also explored themes such as charity and superstition that became important foci in later bingo literature (Griffiths \& Bingham, 2005; Paarlberg et al., 2005; Casey, 2018.)

Working in different countries, King, Dixey and Talbot shared significant interests and impulses. While King sat more conventionally within gambling studies and Dixey and Talbot were leisure researchers, they all looked at women's experiences at a time where there was limited focus on gendered differences among gamblers. They approached gambling as a normal, not pathological, activity, exploring social rather than psychological reasons for gambling and insisting that we look at bingo in its social and structural context.

\section{0 s - Highlighting Harm}

Despite these significant 1980s studies, the following decade saw a pause in bingo research, with some notable exceptions. One was David Hewitt and colleagues' (1994) important Canadian study of gambling harm among Indigenous people in Alberta, where bingo was overwhelmingly the most popular form of gambling. Hewitt et al.'s work was important methodologically as it was conducted by Indigenous interviewers for an Indigenous organisation to inform interventions to benefit Indigenous communities (Little, 1997), and so modelled an ethical approach to research in Indigenous communities (National Health and Medical Research Council, 2018). In what would become common findings in bingo research (Chapple \& Nofziger, 2000; Cousins, 2004; Maltzahn et al., 2019), people gambled, in order of importance, to win money, have fun, and for excitement; nearly one third, however, gambled to be alone (Hewitt et al. 1994). The study went beyond this, however, to break new ground in understanding harm in relation to bingo.

Hewitt et al.'s study was the first that both addressed bingo-related harm and explicitly aimed to inform gambling harm treatment and prevention programs
(Little, 1997). This focus on harm was then new in bingo literature, but the data demonstrated the urgent need to consider it. The study found problem and compulsive gambling could be twice as prevalent amongst Indigenous people as other Canadians (Little, 1997). Like the 1980s research, the study showed the importance of social context, such as the link between gambling harm and having attended residential schools, which were sites of abuse, cultural dislocation and other colonial violence (Parrott, 2014). This is crucial in understanding the study's broader findings that bingo and other forms of gambling were a way to cope with unresolved grief and that problem gambling was found across families and households. This recognition of the clear link between trauma and gambling harm was relatively early in gambling literature (see Hodgins et al., 2010), and was ground-breaking in showing that, under certain conditions, bingo could cause great, and sometimes lifelong, harm.

In another example of notable literature in the 1990s, Jerry Burger (1991) demonstrated how bingo could be a tool to understand other phenomena, studying bingo and lotto to explore questions about personality, the desire for control, and superstitions. Additionally, bingo had a cameo role in pedagogical writing as a public, open and safe site to teach students ethnography (Keen, 1996). Finally, in a rare example of grey literature at this time examining bingo, a comparative history of Australian gambling showed the importance of local context, including regulation, in shaping bingo: for example, in the state of Victoria, the introduction of Electronic Gambling Machines (EGMs) caused bingo playing to plummet (Australian Institute for Gambling Research University of Western Sydney, 1999). The report also highlighted how racism and sexism shaped bingo. For example, while bingo was illegal in many states, the authorities turned a blind eye as it was often played by white people, despite punishing gambling in European and Chinese clubs.

\section{0s - Broadening the Base of Bingo Research}

Hewitt et al.'s ground-breaking research had paved the way for a new focus on harm and the distinct and shared experiences of specific groups. The 2000s broadened the base of bingo research, more fully describing contemporary bingo, providing a historic context, spotlighting both not-for-profit and commercial bingo operators and, through a collection of ethnographic work, bringing a greater focus on older people. Together, these studies painted an increasingly clear picture of bingo, albeit only in Australia, Canada, the UK and US.

Constance Chapple and Stacey Nofziger's (2000) US ethnography was the first of several that decade (Dudar, 2009; Maclure et al., 2006). These were complemented by Canadian studies of older women bingo players (O'Brien Cousins \& Witcher, 2004, 2007) and Australian work on older people in clubs (Breen, 2009). The ethnographic nature of these studies, several of which 
included participant observations, enabled researchers to evoke bingo's atmosphere, culture, rituals and social context, providing a fuller picture of bingo. Supplementing earlier accounts of reasons for playing bingo, they found that bingo helped counter depression and provide cognitive stimulation, and, unlike other gambling sites, welcomed women (Breen, 2009; Dudar, 2009). Bingo was consistently identified as an escape from stress, loneliness and boredom (O'Brien Cousins \& Witcher, 2004). For women experiencing difficulties such as family or financial strain, bereavement or poverty, bingo could offer solace, rejuvenation, a sense of control and identity ( $\mathrm{O}^{\prime}$ Brien Cousins \& Witcher, 2004; Maclure et al., 2006).

Whether described as deviance, imprudence or problem gambling, bingo-related gambling harm received more attention (Chapple, 2000; O'Brien Cousins \& Witcher, 2004; Maclure et al., 2006). Bingo players were found to experience "elements of serious financial, emotional and social risk" (Maclure et al., 2006, p. 175), and feel worry, anxiety, guilt and shame (O'Brien Cousins \& Witcher, 2004; Maclure et al., 2006). Dependent family members were also negatively impacted (Maclure et al., 2006). Harm also came in the form of unfair stereotypes (O'Brien Cousins \& Witcher, 2004). Importantly, Breen (2009) identified the practice in Australia of "loss leading", where clubs used bingo to recruit people to use EGMs, that while more lucrative for clubs were more harmful for players. In a significant shift in the literature, Richard Maclure and colleagues identified an acute tension in bingo: while bingo was often not just harmless but therapeutic for some, for others it was harmful and could exacerbate powerlessness (2006).

These researchers explicitly countered the scholarly neglect of bingo, which Sandra O'Brien Cousins and Brad Witcher argued was due to sexism and ageism (2004), and showed the distinct contributions bingo studies could make. For example, the fact that bingo was a women's game highlighted gendered differences in gambling and harm, itself a neglected area (Maclure et al., 2006). Further, continuing the tradition started by Dixey and Talbot, this body of research centred bingo player's experiences, something that Maclure et al. (2006) contended was then a gap in gambling research.

In a parallel and new development in bingo literature, researchers of not-for-profit management, such as Laurie Paarlberg, Robert Christensen and colleagues (2005), argued that as bingo was increasingly a big business and government revenue raiser, charitable gambling required closer examination. They showed that bingo in the US was a poor fundraiser and exposed charities to the risk of fraud. They later explored the threat of corruption and mission drift for not-for-profit bingo operators (Christensen, 2009). This work is part of a distinct subset in bingo literature that

\footnotetext{
${ }^{4}$ Where valuables are not wagered.
}

uses bingo as a lens to explore charities and regulation (Bedford, 2015; Casey, 2018).

In the first English survey of bingo playing since Dixey and Talbot, Mark Griffiths and Carolyn Bingham (2002) drew attention to bingo players' participation in other forms of gambling, with heavy bingo players and men being more likely to use EGMs. This is significant when considering gambling harm. As a counterbalance to concerns about harm, Benjamin Sobel (2001) found that non-gambling bingo ${ }^{4}$ in community adult day care facilities was more effective than physical activities in increasing short-term memory, concentration, word retrieval and word recognition for people with Alzheimer's disease.

The 2000s also brought a historical focus. Business historian Carolyn Downs (2007, 2009, 2010, 2011) reinforced Dixey and Talbot's portrait of bingo as part of an old tradition of working-class English women's gambling, while contesting several of their findings. In her encyclopaedic cultural, economic, legal and social history of bingo (2009), Downs traced the development of bingo in Britain among working class women, arguing that class is more salient than gender in analysing and understanding bingo in Britain. As an illustration of this, Downs argued that Dixey betrayed class prejudice in characterising bingo as a negative choice driven by lack of other leisure choices, rather than being a legitimate and positive preference (Downs, 2009). Downs found that the social importance of bingo, in contrast to winning, has been overstated, including by Dixey. Downs saw the emphasis on the social side of bingo as both a tactic by commercial bingo operators to make the game more respectable and because players feel cognitive dissonance acknowledging a form of gambling as a pleasurable hobby (2009). Quoting Rowntree's memorable phrase, that poor people would "rather have six penn'orth of hope than six penn'orth of electricity" (Downs, 2009, p. 29.), Downs argued that gambling is a rational way for impoverished people to try for an otherwise unattainable lump sum of money.

One of Downs' key contributions is her analysis of the role of commercial bingo in the 1960s British bingo boom. She described the 1950s transformation of bingo when labour changes resulted in working class people flocking to the seaside for holidays. Once there, the relaxation of every-day morality led people to try the thrilling games of gambling on offer, with bingo particularly popular with women (Downs, 2010, 2011). This introduction laid the foundation for commercial bingo providers such as Mecca to transform dance halls into bingo halls and become remarkably popular and profitable when, in 1960, the UK Betting and Gaming Act opened the door to for-profit bingo. In a departure from the previous focus on charitable operators, Downs' case study showed that as Mecca's profits soared, they perfected ways to increase money-making: 
as well as offering glamour, they sped up games and introduced fast mechanised games during breaks, prefiguring technological changes today (2010). Mecca was also politically strategic. After exposés about protection rackets and money laundering and moral panic about bingo playing, new legislation was drafted explicitly aiming to stop commercial bingo. While the new legislation forced the closure of 90 per cent of casinos, Mecca assiduously promoted bingo as a social game, and while regulation tightened, commercial bingo continued. This framing of bingo persists to this day.

\section{0 - Surveying New Vistas}

With its attention to the power of commercial operators to change the game, Downs' work provides an important bridge to the 2010s, when questions about commercialisation, profit and harm gained more prominence. The literature of this decade grappled with questions of harm for specific groups and over time, as well as the impact of technological and regulatory changes. In a new approach, research used bingo as a tool, for example to improve health, and as a lens to examine issues, from neoliberalism to the power of regulation.

In the decade from 2010, there were more academic articles about bingo than the previous thirty years combined: it is beyond the scope of this work to establish why. One was the first systematic review of academic literature on bingo (Moubarac et al., 2010). Jean-Claude Moubarac, N. Will Shead, and Jeffrey Derevensky noted that the ethnographic bingo studies of the 2000s had departed from earlier work by highlighting the risks and impacts of problem gambling but that little was known about its prevalence or character. Their exploration of rates of play and harm was a significant new contribution. While prevalence rates varied widely across and within countries, they showed a pattern of problem gambling amongst bingo players and recognised that bingo players often also gambled in other ways. They also showed that, in some jurisdictions, bingo playing was more popular with adolescents than previously known. They raised particular concern about adolescents and older people and called for more research on harm.

Their call was answered by Heather Wardle and colleagues' survey (2016) of problem gambling in British bingo clubs, a new development in UK quantitative research on bingo. The study found that a significant proportion of bingo players was at risk of harm and showed that harm was higher among specific groups. Problem gambling was linked to more frequent play, multiple forms of gambling inside and outside clubs and using EGMs. In an important study that found people who gambled monthly on bingo, sports betting

\footnotetext{
${ }^{5}$ Variously called personal electronic terminals (PETs) and play on demand (POD) bingo, PETs/PODs enable simultaneously play of multiple games and can allow bingo play outside live games as well other forms of gambling
}

or in casinos (which had EGMs, table games and other forms of gambling) were more likely to experience harm, Alissa Mazar, Martha Zorn, Nozipho Becker and Rachel Volberg (2020) moved beyond the question of whether specific gambling forms were most harmful to highlight the interplay between gambling forms, involvement (number of forms) and intensity (time and money spent). This helped make sense of data showing that bingo players in some jurisdictions experienced more harm than in others. For example, while prevalence studies have often found bingo to be lowrisk, Per Binde, Ulla Romild and Rachel Volberg (2017) found high rates of gambling harm among bingo players in Sweden. Exploring another factor in harm levels, Wardle et al. (2016) noted the way new technologies were shaping bingo, something soon to be explored by other writers.

Research showed that, while for many years bingo had been the sleepy traditionalist of gambling, the 2010s marked a period of accelerated technological and regulatory change, resulting in the popularising of electronic bingo tablets (PETs or PODs) ${ }^{5}$ and online bingo, ${ }^{6}$ and the expansion of gambling forms allowed alongside bingo (Harrigan et al., 2015; Rockloff et al., 2016; Stead et al., 2016). Kevin Harrigan, Dan Brown and Vance MacLaren argued that electronic bingo represented a fundamental departure from traditional, paper-based bingo as it incorporated higher-risk features drawn from EGM technology. Complementing this, Matthew Rockloff and colleagues (2016) noted that aspects of this new technology could increase harm by exaggerating the illusion of control and likelihood of success. While PETs/PODs risked weakening the distinct conviviality of in-person bingo, Martine Stead and colleagues showed that online operators capitalised on its social nature to recruit players and intensify their gambling. Charity operators, Donal Casey found, were willing to use online bingo for fundraising as it was seen as "soft" gambling: however, while online bingo was less risky than other online gambling, it appeared to be more harmful than "brick-and-mortar" bingo (2018, p. 165).

The 2010s saw a distinct focus on particular groups. For example, following Hewitt et al., several researchers explored the experiences of Indigenous bingo players. Christina Larsen, Tine Curtis and Peter Bjerregaard's 2013 survey of Greenland Inuit people was the first outside Anglophone countries. Nerilee Hing, Helen Breen, Ashley Gordon and Alex Russell (2014) showed the gendered differences in gambling among Indigenous people in Australia, with women more likely to play bingo than men. Surveys of gambling in Indigenous communities were not uniform. In some areas, rates of bingo playing and gambling generally were higher than among non-Indigenous people, while

\footnotetext{
6 The first online bingo website was established in 1998 (Casey, 2018).
} 
in other areas they were lower. In all cases, however, gambling harm was more prevalent and in some more severe (Gill et al., 2016; Larsen et al., 2013; Williams et al. 2016). Similarly, the link between gambling harm and bingo varied (Gill et al., 2016; Williams et al., 2016). Qualitative research in Australia (MacLean et al., 2019; Maltzahn, Briggs et al., 2017; Maltzahn, Vaughan et al., 2017) showed both that bingo provided pleasure, solace and the promise of money in the context of disproportionate trauma, disadvantage and poverty and that some bingo players and their families experienced harm. Exploring social constructions of Canadian bingo players, Jo-Anne Fiske identified how anti-gambling discourse stigmatised predominantly Indigenous women as "bingo addicts" and their children as "bingo orphans" (2015, p. 526). The literature on bingo in Indigenous communities is important in highlighting the link between gambling harm and structural disadvantage.

Other groups $^{7}$ studied included older people (Medeiros et al., 2015; Tse et al., 2012), young people (Martinez-Loredo et al., 2019; Udesen et al., 2019), Pacific people (Alexeyeff, 2011; Kolandai-Matchett, 2017; Fehoko, 2020), women (Palmer du Preez et al., 2019) and gay men (De Anda, 2019). Each focus area enabled important contributions, showing, for example, that bingo was often not seen as gambling (Udesen et al., 2019; Fehoko, 2020), migration changed experiences of gambling (Fehoko, 2020) and older bingo players were more likely to engage in many forms of gambling than other older people (Tse et al., 2012). A broader range of countries was also studied (Larsen, 2013, Fehoko, 2020), highlighting the value in a broader geographic and cultural focus. For example, Gustavo Medeiros and colleagues (2015) found gambling harm was significantly higher for Brazilian bingo players, suggesting that multi-form commercial gambling in Brazilian venues may increase harm, in contrast to charitable bingo in the US.

The next group of researchers continued earlier bingo researchers' practice of using bingo as a window into wider social, political and economic relations (part of an established tradition of examining wider phenomena through gambling) (Bedford, 2019). Exemplifying this, Kalissa Alexeyeff (2011) linked the rapid increase in bingo operations in the 1990s in the Cook Islands to a restructuring of the Pacific nation's economy that pushed many into poverty. In a critique of neoliberalism, Alexeyeff argued that speculation and gambling were a rational, if futile, response to international inequities, whether for individual Cook Islanders adopting bingo as a "job" or the Cook Island government using both risky loans and gambling as fundraising mechanisms. Alexeyeff's expansive contribution to bingo scholarship was followed by equally ambitious work, not least because of the entrance of UK academic Kate Bedford.
To date the most prolific of bingo scholars, over the last decade Bedford (2011, 2015, 2016, 2018, 2019; Bedford et al., 2016) has contended not only that bingo should be studied to correct the historic neglect of working-class and Indigenous women's gambling but that bingo, as much as better-studied casinos or stockmarkets, provided a unique vantage point to examine broader concepts (2019). With a consistent focus on gender, the "everyday" and regulation, Bedford has explored ways the law is "invoked, ignored, strategically evaded or resisted" (2018, p. 15). In the bingo halls Bedford described, whether Canadian or English, "unruly" workers and "notoriously cantankerous" players subvert regulations and safeguard bingo's social side (2018, pp. 34, 24). Nonetheless, Bedford recognised that "bingo-based defiance" cannot arrest the forces reshaping bingo, particularly standardisation and regulation, arguing that rules and regulations homogenise gambling by treating all forms as the same, and so normalise gambling as the "efficient extraction" of money from players by corporations (2018, pp. 35, 34). This standardisation first ignores, and then destroys, the way bingo "produce[s] community cohesion, neighbourhood identity, conviviality, and economics of generosity" (Bedford, 2016, p. 7). Her focus on bingo in cooperatives such as working men's clubs (Bedford, 2019) is a complement to Downs' interest in commercial bingo (2009).

In the biggest study of bingo to date, Bedford and colleagues Oscar Alvarez-Macotela, Donal Casey, Maria Luiza Kurban Jobim and Toni Williams (Bedford et al., 2016) researched venue-based bingo in Brazil, Canada, England and Wales and online bingo across Europe. The study showed the cultural limits of previous depictions of bingo: bingo in Brazil was favoured by middle class and wealthy Brazilians, as well as the working class and by both men and women and rather than being respectable, had a reputation for corruption, money laundering and violence (Williams, 2018). Brazil was also anomalous in other ways. Despite decriminalising bingo in 1993 and running it as a state monopoly, Brazil stood against the global wave of gambling liberalisation and in 2006 recriminalised bingo. Jobim and Williams (2017) contended this showed that theories that gambling liberalisation is almost impossible to reverse were not universally applicable. These authors demonstrate the need to consider bingo in thinking through questions about fairness in gambling regulation, as well as governance, mutual aid and capitalism more widely (Bedford et al., 2016; Bedford, 2019).

Finally, a distinct group of health researchers used non-gambling bingo as a tool, harnessing its familiarity and accessibility, and adapting its form, to educate older people about falls prevention (Flint et al., 2020), vulnerable people about concussion (Wallace et al.,

\footnotetext{
${ }^{7}$ These are self-evidently overlapping groups at times.
} 
2019), children with autism about verbal communication (La Londe et al., 2020) and health professionals about workplace processes (Brown, 2020; Shaw \& Ouchida, 2020). It was integrated into stroke recovery to establish that patients needed cognitive stimulation as well as physical therapy (Bray et al., 2019) and used as a site for health interventions (Evans et al., 2017). This use of bingo's game form resonates with Michael De Anda's argument, drawing on gaming theory, that bingo is a "ludic framework", "a basic and commonly understood play structure that provides a foundation for interpretive design based on folk knowledge and practices" (2019, p. 60). These examples from health settings suggest that beyond its wellestablished nature as a carrier of gambling, the game of bingo is an accessible and plastic form of play that can be adapted for other purposes without stigma.

\section{Major Themes in Bingo Research}

In this review, we aimed to explore key literature on bingo, identifying changes over time and key themes. Our study shows that this body of work paints a vivid picture of bingo as a seemingly simple game offering contradictory experiences, sometimes simultaneously. It is exciting and calming, social but able to be solitary, a game of chance that is cognitively stimulating, and, for many, safely risky. It is, however, concurrently a comfort and a threat to some, particularly those who have experienced trauma and injustice. Despite its social benefits, it is, ultimately, a way to win money or goods, which provides both a thrill and material gain. Importantly, it is now a game in flux, being reshaped by changing technologies, corporate interests and regulatory frameworks. As such, it provides an earlystages case study of significant structural changes in an enduring gambling sector. Arguably, the game and its players have been trivialised, pathologised and dismissed, including by some academics. Nonetheless, as this review demonstrates, paying attention to bingo is illuminating. Bingo studies showcase methodologies congruent with the practice they examine, invite a better knowledge of groups of overlooked gamblers, correct biases in gambling literature, highlight issues of governance and regulation and provide new perspectives on gambling, as well as new ways to analyse other phenomenon. We conclude this survey of the literature by exploring some key themes and contributions from the literature: skill, affect, harm and community, control, co-option and capitalism.

Bingo studies' close attention to class, gender, Indigeneity and place enables fresh perspectives on concepts such as skill. The common depiction of bingo as devoid of skill (Griffiths, 2005; Moubarac, 2010) reinforces negative judgements that bingo players lack intelligence or sophistication. Bingo studies expose the bias in such assumptions. The research shows that the purported lack of skill can be liberating, releasing poor women from the fear that if they fail it is their fault (Dixey 1982) and providing a cover of respectability for women, who cannot be accused of gambling out of selfinterest, as they are demonstrably unable to sway the outcome of the game (King 1990). At the same time, bingo does, in fact, require skills such as hand-eye coordination, mental functioning and memory (Sobel 2001), as the use of bingo in health settings demonstrates. By examining the classed, gendered and racialised ways ideas of skill are constructed, bingo researchers offer a more nuanced, and accurate, account of skill and chance in gambling. This is just one of the ways that a recognition of factors such as class and gender, that bingo invites, can enrich our understanding of gambling and other practices.

In another of its distinct contributions to gambling literature, bingo research offers a deep dive into the neglected area of affect in gambling (Livingstone et al., 2019). Bingo studies show with richness and depth the importance of feelings in bingo, from joy to frustration, happiness to grief, for bingo players and their families (Chapple \& Nofziger, 2000; O'Brien Cousins, 2004; Dudar, 2009; Moubarac, 2010; Fiske, 2015; Wardle, 2016; MacLean et al., 2019; Maltzahn et al., 2019). The vivid quality of players' bingo-related social world gives us an acute example of how people's feelings, and their social connections, interact with their gambling in ways that can both protect against and intensify harm. The fact that this modest game can elicit powerful emotions and create lasting routines and relationships demonstrates why affect must be considered, and, in turn, why bingo is worth studying.

Bingo studies also offer important contributions to understandings of gambling harm. Bingo players' participation in other forms of gambling (Hare, 2015; Wardle, 2016; Armstrong, 2017) highlights multi-form gambling, increasingly identified as a factor in gambling harm (Mazar et al., 2020). Additionally, it shows the way the gambling industry is transforming a relatively low-risk game into more extractive forms of gambling, whether by loss-leading (Breen, 2009; Maltzahn et al., 2017) or new technologies (Harrigan et al., 2015; Rockloff et al., 2016), including regulators' facilitation of this (Bedford, 2019). Bingo researchers also push for expanded notions of harm, such as showing the risks to charities of running bingo (Paarlberg et al., 2005; Casey, 2018). One of the most compelling examples of this is the call to centre fairness, for players, their families and workers, in considerations of gambling and harm (Bedford et al., 2016). This work both takes seriously the possible harm to previously overlooked gamblers and expands standards for assessing the value and dangers of forms of gambling. Crucially, studying changes to bingo shows that it is not inevitable that bingo will become more harmful to players, and research findings provide justification for pressuring regulators to protect the positive elements of bingo and curtail harmful aspects.

Finally, bingo studies resolutely explore issues of power and control, whether by individuals, communities, corporations or governments; they also 
show the constraints on power (Downs, 2007, 2009, 2010; Bedford 2019). Bingo's unclear status as a form of gambling (is it really gambling, is it really harmful, is it charity or commerce, is it controlled by communities or corporations?) makes it an illuminating case-study for examining state regulations and corporate incursions, while at the same time showing the power of ordinary people, even in constrained circumstances. Bingo researchers' interest in overlooked people playing an overlooked form of gambling allows them to show things others have missed: the importance of mutual aid in the history of bingo, the centrality of community for many gamblers, the limits of reductive approaches to gambling that see it primarily in terms of individual benefit and the tension between commerce and community in gambling (Bedford, 2019).

\section{Conclusion}

The expanding bingo literature reveals a unique and previously overlooked form of gambling. In doing so, it contributes to knowledge about bingo players, gambling and gambling harm, as well as broader studies. It can help us explore regulation and liberalisation, tradition and technology, mutual aid and political elites, pleasure and political economy, not to mention class, gender and race.

Reflecting existing bingo research, the material identified was heavily skewed towards Englishlanguage literature from Aoteoroa/New Zealand, Australia, North America and the UK; this allows only a partial picture of bingo. The work reviewed was primarily peer reviewed academic publications; while we sought to include grey literature, we found little, and so may have missed important regulatory and policy treatment of bingo. We are mindful that our overview may well have gaps, particularly where broader work on gambling grapples with bingo.

Four areas of work would further progress bingo studies. First, while recent work has broken beyond the Anglosphere, there is still a need for exploration and comparison of the diverse forms, players, character and histories of bingo internationally. Second, given the rate of change in bingo, analysis of the nature, sources and impacts of these changes would be helpful, with a focus on technology, regulations and corporations. In examining changes, particular attention to harm and fairness, for players, workers and their communities, is needed. Third, in light of the limited research around strategies to minimise bingo-related gambling harm, investigation of regulations and other interventions to promote fairness, protect the benefits of bingo and prevent and constrain harm would contribute to both academic and policy discussions. Finally, responding to the compelling argument that bingo research can illuminate broad topics, we hope many others will step onto that stage.

\section{References}

Alexeyeff, K. (2011). Bingo and budgets: gambling with global capital in the Cook Islands. In McIntyre, M. (Ed.) Managing Modernity in the Western Pacific. University of Queensland Press.

Armstrong, A. C., M. (2017). Gambling activity in Australia: Findings from wave 15 of the Household, Income and Labour Dynamics in Australia (HILDA) Survey (978-1-76016-158-3(PDF)).

Australian Institute for Gambling Research University of Western Sydney. (1999). Australian Gambling Comparative History and Analysis.

Bedford, K. (2011). Getting the bingo hall back again? Gender, gambling law reform, and regeneration debates in a district council licensing board. Social \& Legal Studies, 20(3), 369-388. http://dx.doi.org/10.1177/0964663911407652

Bedford, K. (2015). Regulating volunteering: Lessons from the bingo halls. Law \& Social Inquiry, 40(2), 461-490., http://dx.doi.org/10.1111//si.12100

Bedford, K. (2016). Bingo regulation and the feminist political economy of everyday gambling: in search of the anti-heroic. Globalizations, 13(6), 801-814. https://dx.doi.org/10.1080/14747731.2016.1164981

Bedford, K. (2018). Regulation and resistance in Canadian bingo halls: A socio-legal account. JL \& Soc. Pol'y, 30, 11.

Bedford, K. (2019). Bingo capitalism: The law and political economy of everyday gambling: Oxford University Press. http://dx.doi.org/10.1093/oso/9780198845225.001.0001

Bedford, K., Alvarez-Macotela, O., Casey, D., Jobim, M. L. K., \& Williams, T. (2016). The bingo project: Rethinking gambling regulation.

Belanger, Y. W., R.: Prusak, S. (2017). Tracking the westernization of urban Aboriginal gambling in Canada's Prairie Provinces. International Gambling Studies, 17(1), 1-19. https://dx.doi.org/10.1080/14459795.2016.1244698

Binde, P., Romild, U., \& Volberg, R. A. (2017). Forms of gambling, gambling involvement and problem gambling: evidence from a Swedish population survey. International Gambling Studies, 17(3), 490-507. https://doi:10.1080/14459795.2017.1360928

Bray, E., Slade, P., Yeap, S., \& Coady, J. (2019). 27; Improving patient experience and wellbeing on an acute stroke unit through bingo. Age and Ageing, 48, ii1-ii10. https://dx.doi.org/10.1093/ageing/afz055.27

Breen, H. (2009). Senior citizen bingo players in Australian registered and licensed clubs: A case study at Tweed Heads, New South Wales. Journal of Travel \& Tourism Marketing, 26(4), 383. http://doi.org/ 10.1080/10548400902976513

Brown, T. (2020). B.I.N.G.O! Patient safety. Nurse Educator, 45(1), 60. https://dx.doi.org/10.1097/NNE.0000000000000737

Bryman, A. (2016). Social research methods (Fifth Ed.). Oxford University Press.

Burger, J. M. (1991). The effects of desire for control in situations with chance-determined outcomes: Gambling behavior in lotto and bingo players. Journal of research in personality, 25(2), 196-204. https://dx.doi.org/10.1016/0092-6566(91)90015-1

Casey, D. (2018). The DNA of bingo: charity and online bingo. In Gambling Policies in European Welfare States. Palgrave Macmillan. (pp. 153-171). https://dx.doi.org/ 10.1007/978-3319-90620-1 9

Chapple, C. and Nofziger, S. (2000). Bingo!: Hints of deviance in the accounts of sociability and profit of bingo players. Deviant Behavior, 21(6), 489-517. https://dx.doi.org/10.1080/01639620050184645

Christensen, R. K., Clerkin, R. M., Nesbit, R., \& Paarlberg, L. E. (2009). Light and dark sides of nonprofit activities and the rules to manage them: The case of charitable bingo. Administration \& Society, 41(2), 213-234. https://dx.doi.org/10.1177/0095399708328875 
Cox, J., Maltzahn, K., Lee, H., Whiteside, M., \& Maclean, S. (2021). Bingo, gender and the moral order of the household: Everyday gambling in a migrant community. Journal of Consumer Culture. https://doi.org/10.1177/14695405211022082

DeAnda, M. A. (2019). Masculinities in games for gay male audiences. (Ph.D.). Illinois Institute of Technology.

Dixey, R., \& Talbot, M. (1982). Women, leisure and bingo: Trinity \& All Saints' College.

Downs, C. (2007, Jul 2007). Two fat ladies. History Today, 57(7), 27-29.

Downs, C. (2009). A social, economic and cultural history of bingo (1906-2005): the role of gambling in the lives of working women. VDM Verlag.

Downs, C. (2010). Mecca and the birth of commercial bingo 1958-70: A case study. Business History, 52(7), 1086-1106. https://dx.doi.org/10.1080/00076791.2010.523460

Downs, C. (2011). Two fat ladies at the seaside: gambling in working class holidays 1920-1970. Recording leisure lives: Holidays and tourism in 20th Century Britain, 112(112), 51-73.

Dudar, J. S. (2009). Alone in a crowd: An ethnography of the development and maintenance of community among bingo players. Faculty of Graduate Studies and Research, University of Regina.

Evans, J. M., Connelly, J., Jepson, R., Gray, C., Shepherd, A., \& Mackison, D. (2018). A physical activity intervention in a bingo club: Significance of the setting. Health Education Journal, 77(3), 377-384. https://dx.doi.org/10.1177/0017896917741150

Fehoko, E. S. (2020). From games to gambling: An exploratory study of Tongan-born and New Zealand-born male perceptions and experiences of gambling and problem gambling in New Zealand. Auckland University of Technology.

Flint, J., Madison, M., An Thi, N., Keglovits, M., Emily Kling, S., Yi-Ling, H., \& Stark, S. L. (2020). Fall prevention bingo: Effects of a novel community-based education tool on older adults' knowledge and readiness to reduce risks for falls. American Journal of Health Education, 51(6), 406-412. https://dx.doi.org/10.1080/19325037.2020.1822236

Fiske, J. A. (2015). Bingo: Winning and losing in the discourses of problem gambling. Anthropologica, 525-537.

Gill, K. J., Heath, L. M., Derevensky, J., \& Torrie, J. (2016). The social and psychological impacts of gambling in the Cree communities of Northern Quebec. Journal of Gambling Studies, 32(2), 441-457. https://dx.doi.org/10.1007/s10899-015-9553-y

Green, B. N., Johnson, C. D., \& Adams, A. (2006). Writing narrative literature reviews for peer-reviewed journals: Secrets of the trade. Journal of Chiropractic Medicine, 5(3), 101-117. https://doi.org/10.1016/S0899-3467(07)60142-6

Griffiths, M., Bingham, C. (2002). Bingo playing in the UK: The influence of demographic factors on play. International Gambling Studies, 2(1), 51-60. https://doi.org/10.1080/14459790208732299

Griffiths, M., Bingham, C. (2005). A study of superstitious beliefs among bingo players. Journal of Gambling Issues. Issue 13, March. 1-14 http://irep.ntu.ac.uk/id/eprint/1935/1/197350_2057\%20Griffith s\%20Publisher.pdf

Hare, S. (2015). Study of gambling and health in Victoria. Victorian Responsible Gambling Foundation.

Harrigan, K., Brown, D., \& MacLaren, V. (2015). Gamble while you gamble: Electronic games in Ontario Charitable Gaming Centres. International Journal of Mental Health and Addiction, 13(6), 740-750. https://dx.doi.org/10.1007/s11469-015-9557-y

Hewitt, D., Hodgson, M. Training, Nechi. (1994). Spirit of bingoland: A study of problem gambling among Alberta native people. Nechi Training and Research \& Health Promotions Institute.

Hing, N., Breen, H., Gordon, A., \& Russell, A. (2014). The gambling behavior of indigenous Australians. Journal of Gambling Studies, 30(2), 369-386. https://dx.doi.org/10.1007/s10899-013-9358-9
Hing, N., Breen, H., Gordon, A., \& Russell, A. (2015). Gambling motivations of Indigenous Australians. In Gambling: Cultural attitudes, motivations and impact on quality of life (pp. 29-58). Nova Science Publishers.

Hodgins, D. C., Schopflocher, D. P., El-Guebaly, N., Casey, D. M., Smith, G. J., Williams, R. J., \& Wood, R. T. (2010). The association Between childhood maltreatment and gambling problems in a community sample of adult men and women. Psychology of Addictive Behaviors, 24(3), 548-554. https://doi.org/10.1037/a0019946

Jobim, M. and Williams, T. (2017). Chance developments: Bingo regulation in Brazil. Análise Econômica, 35. http://dx.doi.org/10.22456/2176-5456.70305

Keen, M. F. (1996). Teaching qualitative methods: A face-to-face encounter. Teaching Sociology, 166-176. http://dx.doi.org/10.2307/1318807

King, K. M. (1985). Gambling: Three forms and three explanations. Sociological Focus, 18(3), 235-248.

King, K. M. (1990). Neutralizing marginally deviant behavior: Bingo players and superstition. Journal of Gambling Studies, 6(1), 4361. http://dx.doi.org/10.1007/BF01015748

Kolandai-Matchett, K., Langham, E., Bellringer, M., \& Siitia, P. A. H. (2017). How gambling harms experienced by Pacific people in New Zealand amplify when they are culture-related. Asian Journal of Gambling Issues and Public Health, 7(1), 1-20. https://doi:10.1186/s40405-017-0026-3

LaLonde, K. B., Jones, S., West, L., \& Santman, C. (2020). An evaluation of a game-based treatment package on intraverbals in young children with autism. Behavior Analysis in Practice, 13(1), 152157. https://dx.doi.org/10.1007/s40617-019-00397-8

Larsen, C. V. L., Curtis, T., \& Bjerregaard, P. (2013). Gambling behavior and problem gambling reflecting social transition and traumatic childhood events among Greenland Inuit: A crosssectional study in a large indigenous population undergoing rapid change. Journal of Gambling Studies, 29(4), 733-748. http://dx.doi.org/10.1007/s10899-012-9337-6

Little, M. (1997). The moral dilemma of high stakes gambling in native communities. Laurentian University

Livingstone, C., Rintoul, A., de Lacy-Vawdon, C., Borland, R., Dietze, P., Jenkinson, R., ... \& Winter, R. (2019). Identifying effective policy interventions to prevent gambling-related harm. Victorian Responsible Gambling Foundation.

MacLean, S., Maltzahn, K., Thomas, D., Atkinson, A., \& Whiteside, M. (2019). Gambling in two regional Australian Aboriginal communities: A social practice analysis. Journal of Gambling Studies, 35(4), 1331-1345. http://dx.doi.org/10.1007/s10899019-09858-9

Maclure, R., Smith, J., Wood, S., Leblanc, R., Li, J., \& Cuffaro, A. (2006). Entertainment or imprudence? An ethnography of female bingo players. In The sociology of risk and gambling reader ( $\mathrm{pp}$. 163-184). Routledge.

Maltzahn, K., Vaughan, R., Griffin, T., Thomas, D., Stephens, R., Whiteside, M., \& Maclean, S. (2019). Pleasures and risks associated with bingo playing in an Australian Aboriginal community: Lessons for policy and intervention. Journal of Gambling Studies, 35(2), 653-670. https://dx.doi.org/10.1007/s10899-018-9779-6

Maltzahn, K., Robertson, A., Briggs, A., Haussegger, C., Whiteside, M., \& MacLean, S. (2017). Impacts of gambling on young Aboriginal people in Gippsland and East Gippsland: An exploratory study. La Trobe University, Gippsland and East Gippsland Aboriginal Cooperative.

Maltzahn, K., Vaughan, R., Griffin, T., Thomas, D., Stephens, R., Whiteside, M., MacLean, S. (2017). Gambling in the Sunraysia Aboriginal community. La Trobe University, Mallee District Aboriginal Services. 
Martinez-Loredo, V., Grande-Gosende, A., Fernandez-Artamendi, S. Secades-Villa, R., \& Fernandez-Hermida, J. R. (2019). Substance use and gambling patterns among adolescents: Differences according to gender and impulsivity. Journal of Gambling Studies, 35(1), 63-78. https://dx.doi.org/10.1007/s10899-01809824-x

Mazar, A., Zorn, M., Becker, N., \& Volberg, R. A. (2020). Gambling formats, involvement, and problem gambling: which types of gambling are more risky? BMC Public Health, 20, 1-10. https://dx.doi.org/10.1186/s12889-020-08822-2

Medeiros, G. C., Leppink, E., Yaemi, A., Mariani, M., Tavares, H., \& Grant, J. (2015). Gambling disorder in older adults: a crosscultural perspective. Comprehensive psychiatry, 58, 116. https://doi.org/10.1016/j.comppsych.2014.12.021

Moubarac, J. C., Shead, N. W., \& Derevensky, J. L. (2010). Bingo playing and problem gambling: A review of our current knowledge. Journal of Gambling Issues (24), 164-184. https://dx.doi.org/10.4309/jgi.2010.24.10

National Health and Medical Research Council. (2018). Ethical conduct in research with Aboriginal and Torres Strait Islander Peoples and communities: Guidelines for researchers and stakeholders. National Health and Medical Research Council.

O'Brien Cousins, S., \& Witcher, C. (2004). Older women living the bingo stereotype: 'well, so what? I play bingo. I'm not out drinkin'. I'm not out boozin". International Gambling Studies, 4(2), 127-146. https://doi.org/10.1080/14459790412331296965

O'Brien Cousins, S., \& Witcher, C. (2007). Who plays bingo in later life? The sedentary lifestyles of 'little old ladies.' Journal of Gambling Studies, 23(1), 95-112. https://dx.doi.org/10.1007/s10899-006$\underline{9030-8}$

Paarlberg, L., Nesbit, B., Clerkin, R., \& Christensen, R. K. (2005). Charitable bingo in Indiana: Issues and implications. Nonprofit Management and Leadership, 15(4), 433-448. https://dx.doi.org/10.1002/nml.81

Palmer du Preez, K., Mauchline, L., Paavonen, A.-M., Thurlow, R., Garrett, N., Bellringer, M. E., ... Health, N. Z. M. o. (2019). A mixed methods analysis of gambling harm for women in New Zealand: final report.

Parrott, Z. (2014). Government Apology to Former Students of Indian Residential Schools.

Rockloff, M. D., P: Browne, M: Greer, N: Moskovsky, N: Armstrong, T: Thorne, H: Goodwin, B: Langham, E. (2016). Innovation in traditional gambling products.

Siddaway, A. P., Wood, A. M., \& Hedges, L. V. (2019). How to do a systematic review: $A$ best practice guide for conducting and reporting narrative reviews, meta-analyses, and metaSyntheses. Annual Review of Psychology, 70(1), 747-770. https://doi:10.1146/annurev-psych-010418-102803

Shaw, A. L., \& Ouchida, K. (2020). Geri Consult Bingo! A fun way to orient new fellows to the electronic health record. Journal of the American Geriatrics Society, 68(8), E40-E42. https://dx.doi.org/10.1111/jgs.16682

Sobel, B. P. (2001). Bingo vs. physical intervention in stimulating short-term cognition in Alzheimer's disease patients. American Journal of Alzheimer's Disease \& Other Dementias ${ }^{\circledR}, 16(2), 115$ 120. http://dx.doi.org/10.1177/153331750101600214

Stead, M., Dobbie, F., Angus, K., Purves, R. I., Reith, G., \& Macdonald, L. (2016). The online bingo boom in the UK: A qualitative examination of its appeal. PLoS ONE Vol 11(5), 2016, ArtID e0154763, 11(5). https://dx.doi.org/10.1371/journal.pone.0154763

Stevens, M., \& Young, M. (2010). Who plays what? Participation profiles in chance versus skill-based gambling. Journal of Gambling Studies, 26(1), 89-103.

https://dx.doi.org/10.1007/s10899-009-9143-y
Tse, S., Hong, S. I., Wang, C. W., \& Cunningham-Williams, R. M. (2012). Gambling behavior and problems among older adults: a systematic review of empirical studies. Journals of Gerontology Series B: Psychological Sciences and Social Sciences, 67(5), 639652. https://dx.doi.org/10.1007/s10899-009-9143-y

Udesen, S. E. J., Lenskjold, T., \& Niclasen, B. (2019). Gambling in Greenlandic adolescents. International Journal of Circumpolar Health (Online), 78(1). https://dx.doi.org/10.1080/22423982.2019.1577094

Wallace, J., Covassin, T., \& Beidler, E. (2019). Concussion Bingo: Taking an active learning approach to concussion education with vulnerable populations. The Health Education Journal, 78(3), 315-327. https://dx.doi.org/10.1177/0017896918806935

Wardle, H., Welch, G., Bollen, A., Kennedy, J., \& Gariban, S. (2016). Problem gambling in licensed bingo premises. London: Responsible Gambling Trust.

Whiteside, M., Heyeres, M., Maltzahn, K., Griffin, T., \& MacLean, S. (2019). Intervening in Indigenous gambling: A systematic review of the literature. https://dx.doi.org/10.1177/2158244020947441

Williams, R. J. B., Yale D., Prusak, S. (2016). Gambling and problem gambling among Canadian urban Aboriginals. The Canadian Journal of Psychiatry / La Revue canadienne de psychiatrie, 61(11), 724-731. https://dx.doi.org/10.1177/0706743716661990

Williams, T. (2018). All about that place: The curious case of bingo liberalisation in Brazil. JL \& Soc. Pol'y, 30, 150.

\section{Funding and Conflict of Interest Statement}

The authors have received funding from the Victorian Responsible Gambling Foundation (VRGF).

Beyond funding from the VRGF (above), the authors have not received any financial or professional benefits or interests from this research or its funding.

\section{Acknowledgements}

Our heartfelt thanks to our research partners (Mallee District Aboriginal Services, Gippsland and East Gippsland Aboriginal Services, Sunraysia Mallee Ethnic Communities Council, COTA Victoria), funders of related research (Victorian Responsible Gambling Foundation, MDAS and GEGAC) and colleagues on related research (Ann Briggs, Tiffany Griffin, Clare Haussegger, Jasmine Kirirua, Ashlee Robertson, Raelene Stephens, Darlene Thomas, Annalyse Thompson, Richard Vaughan).

\section{Author Details}

Kathleen Maltzahn has recently concluded work as a Research Fellow in Social Work and Social Policy, La Trobe University, and is currently undertaking a Masters of Philosophy in School of Allied Health, Human Services and Sport, La Trobe University. Her recent research has focused on gambling, including bingo, in and with Aboriginal, Pacific and older communities in Victoria, Australia. Her previous professional work, outside the university sector, focused on violence against women.

Dr John Cox is an Honorary Associate with the School of Humanities and Social Sciences, La Trobe University. He is an anthropologist whose work addresses the intersections of financial practices, developmental aspirations and politics. He is currently Lead Research Consultant on a World Bank study of the social dimensions of climate change in the Pacific. 
Sarah MacLean is an Associate Professor in Social Work and Social Policy, La Trobe University. Her research focuses on alcohol consumption, inhalant use and gambling, all of which can be done legally, but which nonetheless can be detrimental to health and wellbeing. She is interested in developing evidence to support holistic responses for people who experience problems associated with these practices.

Dr. Mary Whiteside is Adjunct Associate Professor in Social Work and Social Policy, La Trobe University. She has a lengthy history of involvement in research and development in health and community settings, including Australian Aboriginal and international contexts. The focus of her research primarily involves social and emotional well-being and community development, using qualitative and participatory research approaches.

Helen Lee is Emerita Professor of Anthropology in the Department of Social Inquiry, School of Humanities and Social Sciences, La Trobe University. Since the 1980s she has conducted research with the people of Tonga, both in their home islands in the Pacific and in the diaspora, particularly in Australia, with a focus on childhood and youth, cultural identity and migration and transnationalism. Her recent research includes an Australian Research Council Linkage Project (2015-19) on the socio-economic status of Pacific Islanders in rural Victoria.

\section{ORCID}

Kathleen Maltzahn

https://orcid.org/0000-0001-7854-7549

John Cox (iD

https://orcid.org/0000-0002-4028-5149

Sarah MacLean

https://orcid.org/0000-0002-8329-0722

Mary Whiteside

https://orcid.org/0000-0002-4607-7113

Helen Lee

https://orcid.org/0000-0002-2379-6940 